\title{
La Necrópolis lbérica de la Solivella: Nuevas visiones, nuevas propuestas
}

\section{The Iberian Necropolis of la Solivella: New visions, new proposals}

\author{
En memoria del doctor Francisco Gómez Bellard
}

Arturo Oliver Foix

Museo de BB.AA. Castellón

aoliver@dipcas.es

Recibido 25/02/2014

Aceptado 31/07/2014

\section{Resumen}

Se hace una revisión de la necrópolis ibérica de la Solivella de Alcalá de Xivert, excavada hace más de cincuenta años, desde una perspectiva metodológica e histórica actual, considerando el uso de algunas piezas como elementos de los rituales funerarios. También se presenta los resultados del estudio antropológico realizado recientemente a los restos óseos.

Palabras clave: Cultura ibérica, necrópolis, ritual funerario

\begin{abstract}
It is drawn a revision of the Iberian Necropolis of La Solivella, in Alcalá de Xivert, excavated more than 50 years ago, from a current methodological and historic perspective, taking into consideration the use of some pieces such as elements of the funerary rituals. At the same time it is shown the results of the anthropological stadium recently done to the osseous remains.
\end{abstract}

Key words: Iberian Culture, Necropolis, Funerary Ritual.

\section{ExCAVACIÓN Y ENTORNO ARQUEOLÓGICO DE LA SOLIVELla}

Los trabajos agrícolas realizados con tractor en una finca propiedad de Bautista García Marín, situada en la partida de la Solivella o Calvari de la localidad de Alcalà de Xivert, que se llevaron a cabo en 1961, sacaron a la luz los restos de una necrópolis ibérica. El hecho se puso en conocimiento de las autoridades locales, quienes a su vez lo trasmitieron al director del Museo de la Diputación de Castellón, el cual puso la situación en manos del director del SIP de la Diputación de Valencia Domingo Fletcher, quien fue el encargado de realizar una prospección durante cuatro días de ese mismo mes que dio como resultado la excavación de 28 sepulturas y la recupera- ción de materiales cerámicos y de bronce que estaban esparcidos por el campo roturado.

El material localizado en superficie y en las excavaciones tras su restauración, fue estudiado y posteriormente publicado en 1965 en una monografía en la cual se describieron las piezas recuperadas y se llevó a cabo una búsqueda de paralelos con el fin de otorgarle una cronología al yacimiento, teniendo en cuenta especialmente los elementos de bronce y un escarabeo (Fletcher, 1965).

El yacimiento lo conformaba un conjunto de enterramientos homogéneo que se caracterizaban por las sepulturas en urnas, especialmente de galbo bitroncocónico, variantes de la forma conocida como pithoi, y de orejetas perforadas. Urnas que al parecer fueron situadas en 
un hoyo sin ningún tipo de estructura que las protegiera, a lo sumo algunas piedras para nivelarlas por su base.

Este yacimiento venía a sumarse a otros restos de necrópolis que habían sido localizados en el valle de Alcalá desde el siglo XVIII, y que se conocían a través de la bibliografía. Es el caso de los provenientes de la partida del Corral de Royo localizados en 1791 (Valcárcel, 1985), los de la partida del Mas, del que tan solo se sabe que se encontraron siete vasijas con varias figuras, anillos y cadenas (Fletcher, 1965: 7) o los de la finca de Dimas Bosch, al parecer con un hallazgo de 16 urnas, y en otros puntos del término de Alcalá (Oliver, 1981: 207-208). También en 1864 en los alrededores del Tossalet se localizaron dos urnas al construir una noria, y en ese mismo año debido a los trabajos de la construcción del ferrocarril se localizaron diecinueve urnas más (Gusi, Oliver, 1986), posiblemente las que se citan a veces como provenientes de la partida de la Palaba. Estos hallazgos se han ido relacionando en la diferente bibliografía desde el propio estudio de la Solivella (Fletcher, 1965: 7 ss) hasta los trabajos posteriores de recopilación referidos a necrópolis ibéricas (Gil-Mascarell, 1973; Oliver, 1981).

Un poco más al sur ya en el llano litoral, se encuentran hallazgos de urnas en la zona de Cap i Corb en la localidad de Alcalá, y cercano a este punto en la zona de Torrenostra de Torreblanca, de un lugar indeterminado, provienen los restos de unas posibles urnas y material de bronce que conformarían enterramientos ibéricos, los cuales se conservan en el Legado F. Esteve en el Museo de BB.AA. de Castellón. Ambos yacimientos permanecen inéditos.

Los asentamientos ibéricos de la zona en donde se ubica la necrópolis de la Solivella, actualmente se constatan en el Castell de Xivert, a una distancia de 1'5 $\mathrm{km}$., en el cual se han localizado niveles de los siglos VII y VI a.C. (Neumaier, et al., 1998) También en el yacimiento del Palau se han recogido materiales que pueden denunciar una ocupación de estos siglos (Salvador, 1979), asentamiento que dista casi dos kilómetros de la necrópolis. Relacionado topográficamente con los enterramientos localizados en 1864 ya en el llano litoral de Torreblanca Cabanes, en la partida de la Palaba se sitúa el yacimiento de Els Tossalets. Podríamos cerrar la relación de estos asentamientos con Els Pasquals de Torreblanca, situado en las primeras colinas que cierran el llano de Torreblanca Cabanes, a 4'5 kilómetros de la zona de Torrenostra. En el propio centro de la localidad de Alcalà, en la calle San José, al realizar unas conducciones telefónicas se localizó cerámica ibérica y de barniz negro, así como dos cabezas de équido (Oliver, 1990). Debido a que el hallazgo se limitó a la anchura de la zanja y que no hubo un seguimiento, no se puede saber si corresponde a un asentamiento, a los restos de un lugar de enterramiento o de algún tipo de depósito cultual.
Destaca de la zona en cierta medida, la presencia de tantos puntos de enterramiento frente a los que se pueden identificar como asentamientos, así mismo la gran distancia que hay entre ambos tipos de yacimiento. Ello podría indicar la existencia de un poblamiento disperso cuyos restos han desaparecido debido a su escasa entidad material.

Así pues, el término municipal de Alcalà de Xivert, tanto en su parte que se encuentra en el valle como en el llano litoral, es rico en hallazgos pertenecientes a un momento del Ibérico Antiguo, aunque debido a que son materiales localizados de forma casual y hace años, los datos que tenemos de estos abundantes hallazgos aportan una información relativa al conocimiento de la Cultura Ibérica de la zona.

\section{LAS NECRÓPOLIS DEL GRUPO SOLIVELLA}

La necrópolis de la Solivella juntamente con la necrópolis tarraconense de Can Canyis en el término municipal de Banyeres (Vilaseca, 1963), inauguraba una serie de enterramientos ibéricos que presentaban unas características similares. Una cronología, entre la segunda mitad del siglo VI a.C. y finales del siglo siguiente o a lo sumo del IV a.C., y la tipología del enterramiento se uniformaba al situarse las urnas en hoyos sin estructuras externas de protección o señalización. También un parecido tipo de material, tanto cerámico como metálico da unidad al conjunto de las necrópolis.

La historiografía tal y como se publicaban los diferentes hallazgos y excavaciones, iría conformando un conjunto de necrópolis con el mismo ritual funerario ibérico en torno al río Ebro. Es el caso de la necrópolis de Milmanda de Vimbodi (Ramón, 1995), de la Oriola en Amposta (Esteve, 1974), Mas de Mussols de la Aldea (Maluquer, 1987), Mianes en Santa Bárbara (Maluquer, 1987), El Puig de la Nau de Benicarló (Meseguer, Giner, 1983), los enterramientos del ferrocarril de Alcalà de Xivert (Gusi, Oliver, 1986), el Mas Nou de Bernabé entre los términos municipales de Tirig y Salzadella (Oliver, 2005). A ellos se tendrían que unir las menciones de enterramientos ibéricos que hay en la bibliografía y que proceden del Bovalar de Benicarló (Esteve, 1966), Mas de Caperó de Traiguera (Oliver, 1981), o los mencionados más arriba de la zona de Alcalà de Xivert. Unas necrópolis con características similares, pero situadas fuera del entorno del río Ebro, sería el caso de la localizada en los términos valencianos de Gátova (Aranegui, 1979), de Zarra (Martínez, 1989), de Gandia (Pérez, et al., 2011), así como también las alicantinas del Molar de San Fulgencio (Peña, 2003) y Altea la Vella de Altea (Morote, 1981) (Fig. 2). Todas ellas con cronologías centradas en los siglos VI y V a.C. La datación más antigua la darían los escarabeos, todos ellos de la primera mitad del siglo VI a.C. (Graells, 2010,55), aun- 
que el conjunto de los materiales locales nos lleva a datar los enterramientos a partir de finales de este siglo y durante toda la centuria siguiente. No es extraña en la arqueología ibérica tanto en ámbitos sepulcrales como domésticos, la localización de materiales foráneos en conjuntos locales más modernos que la importación, seguramente debido al valor económico y social que tendrían las cerámicas o los abalorios en este caso, provenientes del comercio mediterráneo.

Con características materiales y rituales de este conjunto de necrópolis pero con cronologías más modernas se podrían incluir la de Torre la Sal de Cabanes (Flors, 2009) cercana a la Solivella, el Torrelló del Boverot de Almassora (Clausell, 1999), o la de la Serreta de Alcoi (Cortell, et al., 1992), y posiblemente la Albufereta de Alicante (Rubio, 1986) con cronologías centradas en el siglo IV y III a.C. especialmente. Podemos citar también la necrópolis de La Punta de Orleyl, aunque la destrucción que ha sufrido no permite conocer muy bien sus características, pero sería la que presenta la cronología más amplia, desde el siglo VI al II a.C. (Lázaro, et al., 1981).

Las características de estas necrópolis como hemos dicho se encuentran en el tipo de ritual. Una cremación del cuerpo y de los materiales de la indumentaria, de la cual se recogen de la pira los restos óseos que se limpian y se rompen en trozos más pequeños para ponerlos en la urna cerámica. También se recogen los materiales metálicos, como es el caso de las hebillas de cinturón, las fíbulas, cadenillas y otros colgantes y partes del armamento defensivo. Las urnas se depositan en la necrópolis dentro de un hoyo sin ninguna construcción arquitectónica que la proteja. En la concavidad se situarán otras piezas, especialmente algunas puntas de lanza, cuchillos afalcatados y falcatas, arma esta última que es poco abundante. Esta espada y algunas puntas de lanza más grandes suelen estar dobladas, por lo tanto inutilizada, frente a la mayoría de las puntas de lanza y los cuchillos afalcatados, tal vez porque las primeras, especialmente la falcata, se consideran elementos más personales. En una excavación reciente y por tanto mejor documentada, en la Bassa del Mas de Santa Magdalena, las puntas de lanza que acompañan a los enterramientos se doblan en torno a la urna a la vez que se adaptan al hoyo. Por tanto ello podría indicar tan solo una adaptación al espacio de enterramiento, ya que los otros materiales que caben en él hoyo no se destruyen.

También en el ajuar se sitúan otros elementos de la indumentaria a parte de los quemados en la pira, es el caso de cuentas de collar, fibulas, colgantes, broches.

En cuanto a las vasijas son dominantes en los siglos VI - V a.C. las formas de tipo pithoi y de orejetas. El primero de ellos se encuentra en la zona a partir del siglo VII a.C. con los pithoi fenicios, imitados posteriormente por los alfareros locales, que son las formas que sirven de urna. La vasija caracterizada por las llamadas orejetas perforadas es también de las primeras que produce la alfarería ibérica. Se encuentran ya en el siglo VI a.C., en donde son hechas a mano y a torno, para después a finales del siglo VI y V a.C., aplicar este elemento de cierre a una gran variedad de formas como vemos en la Solivella. Es una vasija que posiblemente tenga su origen en el sudeste peninsular (López, 2002; Sardá, Graells, 2004-2005), zona en donde hay una fuerte influencia de la cultura material fenicia.

El tipo de piezas localizado en estas necrópolis, indica unas características de indumentaria muy homogénea, debido especialmente a la presencia de abundantes elementos de bronce, como es el caso de las hebillas en algunos casos de considerable tamaño, fibulas y colgantes, en donde sobresalen las representaciones de animales, carneros y palomas, típicos de la zona en la que se encuentran este tipo de enterramientos. En cuanto al armamento defensivo, es también similar, discos corazas y grebas con decoración repujada a base de líneas y hoyuelos, frente a una falta de cascos de bronce.

Se desconoce el tipo de señalización que habría en superficie para identificar las urnas, si es que lo hubo, ya que éste seguramente sería perecedero y no se han localizado en ninguna de las necrópolis mencionadas, lo que señala una diferencia con las complejas construcciones funerarias de la zona del sudeste, pilares estela, torres, túmulos escalonados, etc., que dan una imagen más perdurable de la persona allí enterrada, indicando a través de la construcción funeraria la importancia económica y social que tenía en vida el finado. Ello es una muestra de la diferencia de los valores simbólicos entre ambas zonas.

Estas necrópolis como es habitual en la Cultura Ibérica se localizan en los alrededores de los poblados, aunque en el caso de la Solivella, tal y como se ha comentado, ésta se encuentra a cierta distancia. Al parecer las necrópolis se ubicarían junto a los caminos de acceso a los asentamientos.

\section{El RITUAL FUNERARIO}

Cuando se publicaron los hallazgos de este conjunto de necrópolis, especialmente la Solivella que fue de las primeras, debido al estado de la cuestión en que se encontraban los estudios sobre la Cultura Ibérica en general y de las necrópolis en particular, los diferentes investigadores se limitaban generalmente a relacionar los materiales y buscar los paralelos y adscripción cultural con el fin de otorgarle una cronología al conjunto de la necrópolis. Los nuevos enfoques de la investigación van más allá de este mero estudio material para adentrarse en problemáticas sociales, rituales y de ordenación de la necrópolis.

Hoy en día no podemos concebir un estudio sobre una necrópolis en el que no esté presente los análisis 
antropológicos de los restos cremados y un acercamiento a toda problemática ritual de la ceremonia del enterramiento y del planteamiento y organización de la necrópolis. Hace años ya presentamos un pequeño estudio sobre la posibilidad de que algunas de las vasijas que se denominan urnas en la publicación inicial de la Solivella, pudieran pertenecer a vasijas que formaron parte no del enterramiento propiamente dicho sino de su ritual (Oliver, 1986), estudio que después de más de veinticinco años y de ser de los primeros que se realizaban sobre esta cuestión, queremos ampliar tras la nueva revisión de los materiales y especialmente del estudio antropológico realizado después de más de cincuenta años de la excavación del que ha sido un yacimiento de referencia en la historiografía de la Cultura Ibérica.

Lamentablemente ni el registro arqueológico que se obtuvo en la excavación, ni el cuidado que se ha tenido con los materiales durante este más de medio siglo que han pasado por diferentes almacenajes, per- miten tratar el tema como sería de desear, pero si aportar nuevos datos o al menos una mirada diferente a la inicial. No obstante algunos materiales de la necrópolis pueden acercarnos a esta problemática (Fig. 1).

\section{La ofrenda}

Una parte del ritual funerario es la ofrenda y la libación que se realiza durante la ceremonia que da sepultura al difunto. Un ritual que podemos reseguir a partir de la forma de las vasijas cerámicas y su posible función, como es el caso del vaso caliciforme, la enócoe y el plato.

Una de las vasijas localizadas entre los materiales destruidos por el tractor es una vasija caliciforme (Fletcher, 1965: 15, fig. 8, 13, lám XLVIII,1). La característica del hallazgo no permite asegurar la función que tuvo en la necrópolis, que en un principio se consideró como urna. No obstante, las vasijas de forma caliciformes está sobradamente demostrado que tuvie-

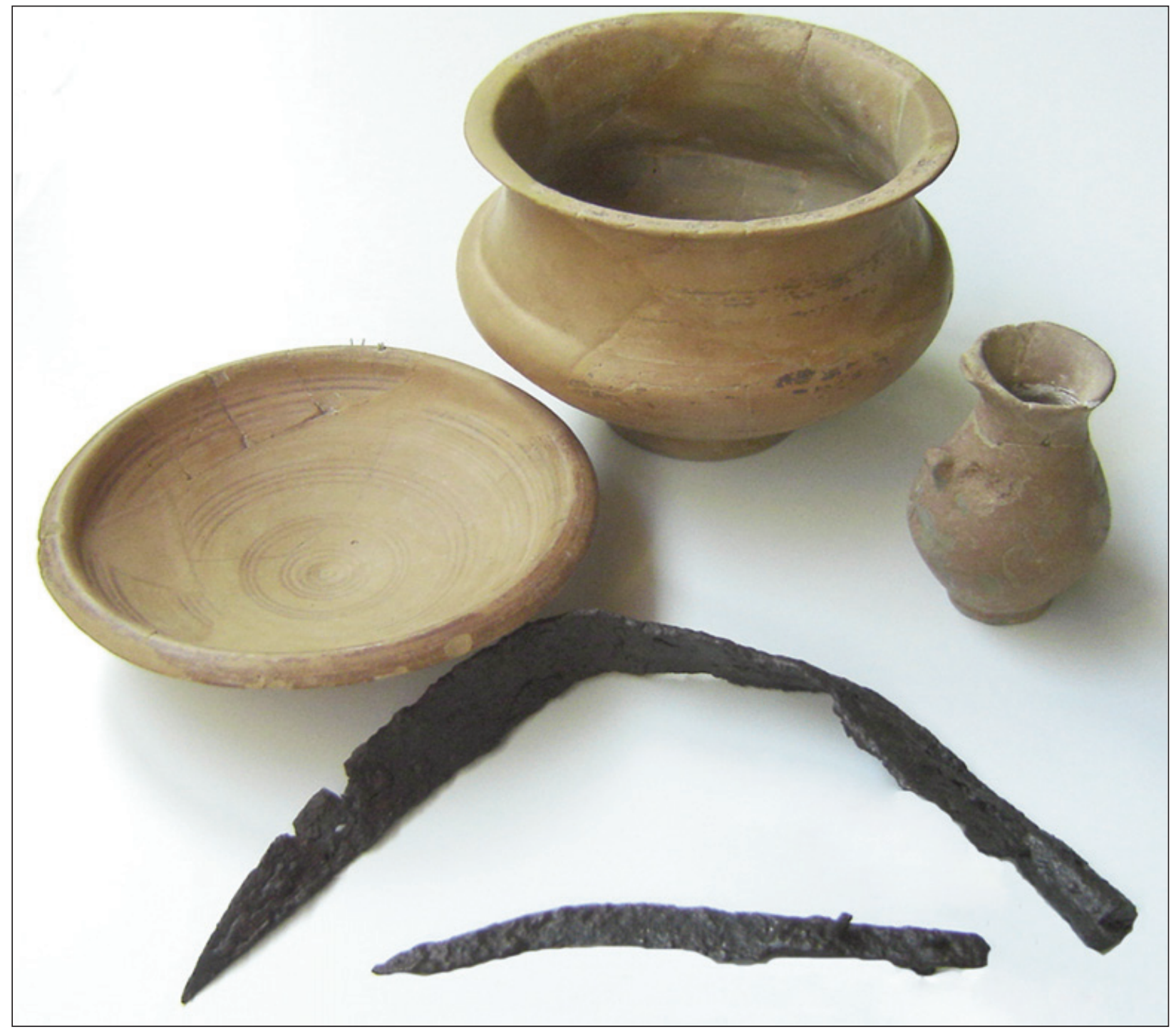

Figura 1. Conjunto de piezas de uso ritual de la Solivella 


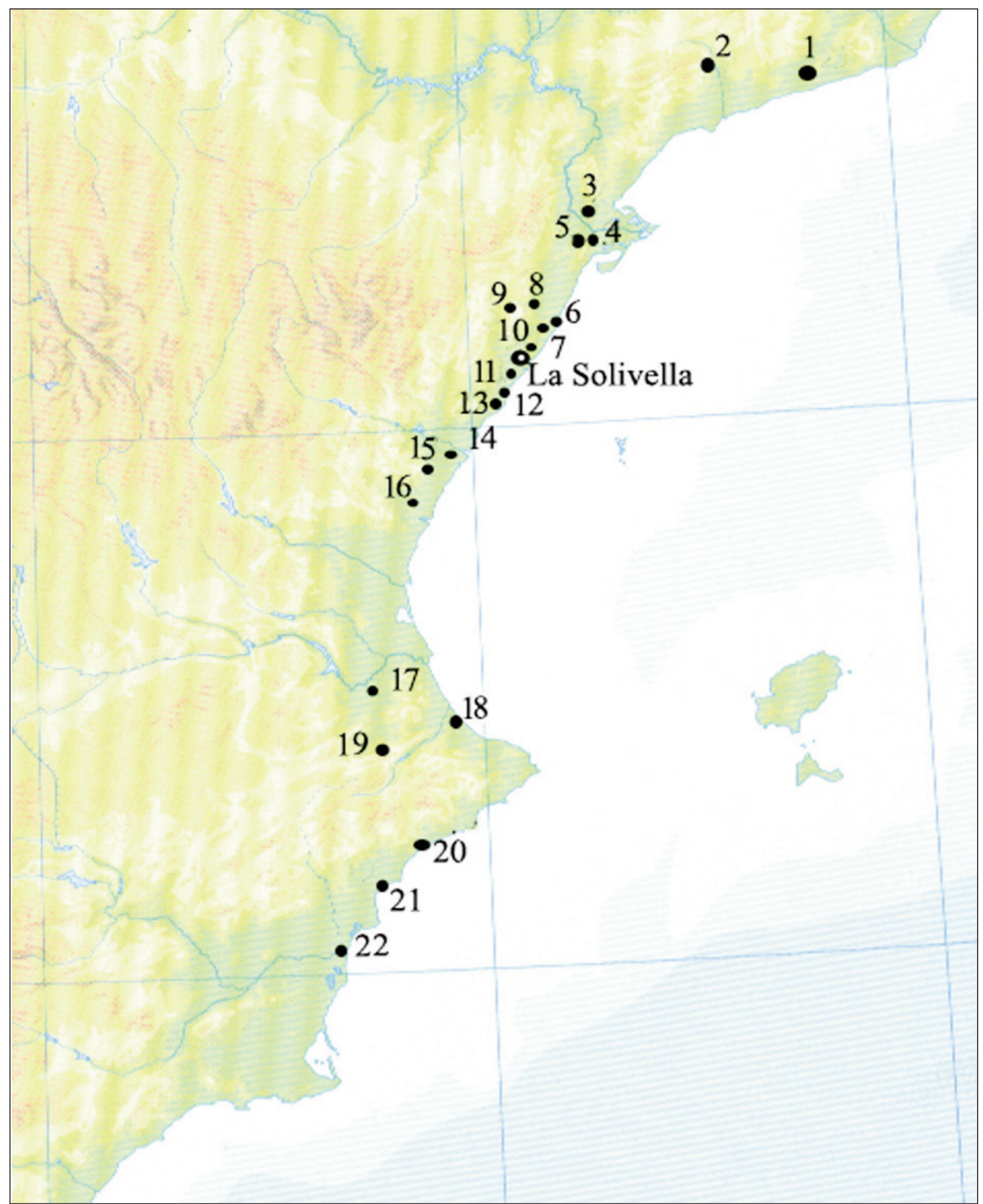

Figura 2. Distribución de las principales necrópolis del grupo Solivella

1.- Can Canyis de Banyeres • 2.- Milmanda de Vimbodi • 3.- Mas de Mussols de 1'Aldea • 4.- La Oriola de Amposta 5.- Miames de Santa Bàrbara • 6.- Puig de la Nau de Benicarló • 7.- El Bovalar de Benicarló

8.- Mas de Caperó de Traiguera • 9.- Mas Nou de Bernabé de Salzadella-Tirig • 10.- Bassa del Mas de Santa Magdalena

11.- Baixador d'Alcossebre de Alcalà de Xivert • 12.- Cap i Corp de Torreblanca • 13.- Torre la Sal de Cabanes

14.- Torrelló del Boverot de Almassora • 15.- La Punta de la Vall d’Uixó • 16.- La Mina de Gátova

17.- Las Peñas de Zarra • 18.- La Vital de Gancia • 19.- La Serreta de Alcoi • 20.- Altea la Vella de Altea 21.- La Albufereta de Alicante • 22.- El Molar de San Fulgencio 
ron un uso ritual, como depósito de ofrendas o vaso de libación, como se puede comprobar especialmente en los pequeños vasos de las cuevas santuario ibéricas, en donde suele ser la forma cerámica predominante de estos contextos (González, 2009; Martínez Perona, 1992). Esta funcionalidad está así mismo identificada en la estatuaria ibérica, en donde son frecuentes los oferentes con este tipo de vasijas, se ve por ejemplo en los bajorrelieves, como el sillar de esquina del monumento funerario de Osuna (Sevilla), en donde una dama en cada parte del sillar, lleva en su mano izquierda un vaso de esta forma. En el Cerro de los Santos hay una estatua representando una pareja de oferentes con la vasija, así como la denominada Gran Dama, y otra dama con la misma representación. El exvoto número de inventario del MAN 22684 procedente de Despeñaperros, aunque sin seguridad, también es una dama con este tipo de vasija (Prados, 1992, 259). Por otra parte, los vasos de tesoros como el del Castellet de Banyoles de Tivissa que tiene diez vasijas caliciformes de plata (Serra, 1941) o el vaso también argenteo del Tesoro de Salvacañete de Cuenca (Cabré, 1936; Raddatz, 1969), tienen esta forma. Son piezas relacionadas indudablemente con rituales.

Así pues, la vasija proveniente de la necrópolis de Alcalá tiene muchas posibilidades de que sea un contenedor de algún tipo de ofrenda o de una ración del festín funerario, provenientes del posible sacrificio del animal que suele formar parte de los rituales funerarios. Ofrendas que en las necrópolis de este tipo se han propuesto también a partir de la presencia de pequeños vasos hechos a mano de pasta tosca (Maluquer, 1987a, 64 , fig. 16), y que se dan en otros lugares relacionados con enterramientos, como es el caso de la Escudilla de Zucaina (Gusi, 1971: fig, 16,2 y 17, 11 bis), o la necrópolis de La Mina de Gátova (Aranegui, 1979: fig. 5).

\section{La libación}

La pieza numerada como urna 19, que tal y como indica Fletcher (1965: 34) "ignoramos si, en realidad, constituyó una sepultura o pudo formar parte del ajuar de alguna otra", es una enócoe, que indudablemente no hizo las funciones de urna, sobre todo por sus pequeñas dimensiones, 83 x $131 \mathrm{~mm}$. Está hecha con pasta gris, al igual que la enócoe del Mas dels Mussols . Debido a que el borde se encuentra roto, así como el asa que le falta, no se sabe si tuvo pico vertedor.

Estas vasijas contendrían los líquidos sacralizados tras el correspondiente ritual, que se verterían como libación por el difunto, tal y como está demostrado en la iconografía mediterránea, de la que podemos señalar la escena de libación de una crátera de campana hallada en Galera. No son extrañas las jarras en las necrópolis como vemos en la tumba 54 de Mianes que ésta si parece que al finalizar sirvió de urna (Maluquer, 1987: fig. 5), y en el Mas de Mussols, en donde hay una enócoe que se considera fenicia en el ajuar de una tumba (Maluquer, 1987 a: fig. 12). En la necrópolis de la Mina de Gátova hay dos enócoe que imitan una forma griega (Aranegui, 1979: fig. 9, 10).

Otra forma cerámica que consideramos podría haber sido usada en el ritual de libación son los platos generalmente muy abiertos y no muy hondos, a veces con borde de ala o borde pendiente, y siempre con base anular. En la excavación de la Solivella se recogieron un total de siete ejemplares de esta forma de pieza cerámica que se consideró hacían las funciones de tapadera de algunas urnas. Cinco de ellos se localizaron entre los restos de la zanja realizada por el tractor que localizó la necrópolis al hacer la transformación agrícola. Otras dos se obtuvieron durante la excavación. Uno con la urna 23 la cual apareció "muy destrozada y con ella algunos fragmentos de la tapadera" (Fletcher, 1965: 36), el otro plato con la urna 28 que estaba "cubierta con tapadera-plato" (Fletcher, 1965: 41). Seguramente por este hallazgo se relacionaron las siete piezas como tapaderas de urnas. En otras necrópolis también se considera la función de tapadera, aunque en algunas ocasiones el plato aparece dentro de la urna roto o estaba junto a la urna, lo que llevaba a pensar en que había caído, en otros casos si que hacia las funciones de tapadera. Indudablemente este tipo de vasija como última función pudo realizar la de cubrir las urnas cerrando las vasijas que eran de tipo pithoi y que por tanto no tendrían una tapadera propia. Pero anterior a este destino final los platos también pudieron hacer la función de pátera de libación dentro del ritual funerario. Tengamos en cuenta que las urnas, o al menos la morfología de las vasijas que sirvieron como contenedores funerarios, son también vasijas que sirven como contenedores de alimentos y que se encuentran así mismo en ambientes de almacenaje, y seguramente una vez vacíos del contenido correspondiente servirían para depositar los restos cremados del finado. Por tanto, los platos también podrían haber sido utilizados para otras funciones anteriormente. El verdadero simbolismo y la función finales de un objeto nos lo dirá en ocasiones el contexto en el que se encuentra más que el propio objeto.

Hay platos en otras de las necrópolis similares a la Solivella, uno en el Mas de Mussols, cubriendo la tumba 24, posiblemente según su autor, de cerámica gris de importación (Maluquer, 1987: 48). También hay en la necrópolis de Mianes en la tumba 26 y en la 34 (Maluquer, 1987: fig.4, 5), así como en las necrópolis de la Mina de Gátova (Aranegui, 1979: fig. 7) y en la de las Peñas de Zarra (Martínez, 1989: fig. 22, 40).

A partir del siglo IV a.C. en la Cultura Ibérica con la introducción de la decoración figurada, hay platos decorados con peces que son utilizados en los contextos funerarios (Aranegui, 1996), pues no se puede olvidar que el destino final de las personas en las culturas 
mediterráneas suele encontrarse a la otra parte de una laguna o río, como el caso de la Estigia, siendo los peces, por ejemplo los delfines, quienes portan el alma del difunto más allá del agua. Por tanto, hay una relación entre el rito funerario y los platos a través de esta iconografía. Que son platos usados para las libaciones lo demuestra que en algunos ejemplares se copia la forma Lamboglia 63 de la cerámica de barniz negro, la cual se utiliza para este uso cultual (Aranegui, 1996: 409). Estos platos decorados con peces tienen cierta relación con los platos de la Solivella, es el caso de su borde pendiente, o su última función como tapadera. Este tipo de platos también se han localizado en el yacimiento albaceteño de Libisosa de Lezuza formando parte en un ritual de ofrendas y libaciones (Uroz, 2012: 65).

En el yacimiento con posible función de culto de carácter necrolátrico de la Escudilla de Zucaina (Gusi, 1971) con una cronología similar a la Solivella, se localizaron un alto porcentaje del tipo de platos que aparecen en la necrópolis de Alcalá, lo que podría reforzar el uso de esta forma como elemento cultual.

Así pues, estos platos bien pudieron haber hecho las funciones de pátera libadora en el ritual funerario, función que en el sur y en el sureste peninsular en esta época lo están haciendo las pateras o braserillos de manos, que tienen una clara tradición oriental, que aparecen en las necrópolis (Cuadrado, 1966). En el noreste peninsular hay también pateras metálicas en necrópolis ibéricas como la de la Granja Soley de Santa Coloma, el Coll del Moro de la Serra d'Almos y la Pedrera de Vallfagona (Munilla, 1991). Hay que indicar que la presencia de platos cerámicos como tapas y como platos libadores está especialmente localizada entre el sudeste y el río Ebro, zonas en donde no hay páteras metálicas en las necrópolis, ya que del grupo del nordeste la proveniente del Coll del Moro en la Serra d'Almors es la situada más al sur, y las pateras de braserillo de las necrópolis alicantinas como el Puntal de Salinas, el Molar de San Fulgencio y la Albufereta de Alicante (Cuadrado, 1966) forman la línea fronteriza de las situadas más al norte del grupo de pateras del sur peninsular. Aunque hay que indicar que sí que existen fuera de contextos funerarios, en asentamientos como en el Cabezo de Alcalá de Azaila (Teruel), El Castellet de Banyoles de Tivissa (Teruel) y en la Bastida de les Alcuses de Moixent (Valencia) (Cuadrado, 1966: 31, 33). Especial mención merece la patera de plata del Castellet de Banyoles de Tivissa (Serra, 1941), o la de Perotito en Santisteban del Puerto de Jaén que tienen una iconografía relacionada con el mundo funerario (Griñó, Olmos, 1992). No obstante señalemos que en muchos casos la patera se ha identificado a través de las asas o de los enganches de estas con el recipiente, y como mucho un fragmento de borde, por tanto cabría también la posibilidad de que sean calderos.
Estas pateras ya sean por encontrarse en necrópolis junto a jarras de bronce o por su iconografía, nos indican que en el ritual funerario se hacían libaciones.

La libación se realiza pasando la ofrenda líquida que podría ser agua, vino, hidromiel, o la sangre del animal sacrificado, según los datos que tenemos de otras culturas mediterráneas, de una jarra a una pátera, bandeja, phiale, o en este caso llamémosle plato. La base anular de estos platos de la Solivella harían las funciones del umbo-omfalo. Libaciones que se podrían hacer tanto para ofrecerlas a los dioses como a los difuntos. Una escena de libación la podemos ver en un bajorrelieve del Santuario de Torreparedones, una pieza de época tardía, en donde se representa una pareja junto a un león sobre una columna realizando una libación (Serrano, Morena, 1988). Las representaciones de otras libaciones ibéricas las recoge T. Moneo (2003: 374).

Estos platos se sitúan encima de la urna boca abajo, hecho que cabe la posibilidad de que sea una posición meramente funcional y de semejanza con la posición de lo que son tapaderas propiamente dichas, aunque el ajuste entre urna y tapadera sería mejor poniendo el plato boca arriba, con la base dentro de la urna. Esta posición invertida de los platos podría ser consecuencia del ritual, ya que en Libisosa de Lezuza, y en un contexto ritual en un hoyo de ofrendas se localizaron micro-escudillas, platos y caliciformes en esta posición, los cuales fueron depositados con cierto cuidado desde el interior mismo de la fosa, hecho que H. Uroz ha relacionado con otros contextos cultuales y funerarios mediterráneos, concretamente con rituales de ofrenda y libación de carácter ctónico de la Magna Grecia y del Mediterráneo oriental como en Creta y Chipre (Uroz, 2012: 35, 438).

Por tanto en la necrópolis de la Solivella se encuentran las dos piezas necesarias para la ejecución de la libación en este caso posiblemente dedicada al difunto, la jarra y los platos. Una práctica ritual que suele ir unida al sacrificio ya que la sangre sería recogida y depositada en recipientes junto a otros líquidos, como cereales, vino leche tal y como indica T. Moneo (2001: 375).

\section{El sacrificio}

En los trabajos de campo de la Solivella se localizaron siete cuchillos afalcatados en las sepulturas excavadas, además dos más en superficie, y también de superficie provienen dos cuchillos largos afalcatados que se encuentran doblados al contrario que los pequeños, hecho que se observa también en las puntas de lanza. Estos dos últimos son más largos de lo habitual y presentan una empuñadura de hierro cilíndrica que cubre al alma del cuchillo, y a su vez ésta iría recubierta por un material perecedero. De los dos cuchillos que se encontraron (Fletcher, 1965: lam. XVI, 2 y 5), 
tan solo se conserva uno, que tiene una longitud de 44 centímetros de filo frente a la media de 15 centímetros que tienen los otros cuchillos afalcatados pequeños.

Los cuchillos pequeños se suelen relacionar con el armamento de los enterrados, y en algunos casos se considera que formarían un juego con la falcata, pues en ocasiones y durante el Ibérico pleno se encuentra adherido a ella por la vaina, arma de la que tan solo hay una empuñadura en toda la necrópolis de la Solivella. No obstante también se ha considerado que estos cuchillos jueguen un papel de prestigio, como podría indicar su representación en la estela de Altea la Vella de Altea (Morote, 1981). Otra función que se ha considerado para este tipo de cuchillo es la sacrificial en el rito funerario (Quesada, 1997: 167), tradición que podría venir de las culturas mediterráneas orientales, en donde por ejemplo en Grecia este tipo de cuchillo afalcatado es el típico del sacrificio. Quedaría patente esta función en la existencia de estos cuchillos tanto en necrópolis como en santuarios en los cuales se relaciona con restos de animales.

La función de sacrificio de los cuchillos afalcatados, especialmente los dos de mayor tamaño con empuñadura cilíndrica, se constata en la escultura a partir del bajorrelieve de Pozo Moro en donde se representa un personaje fantástico blandiendo un cuchillo y procediendo a un acto de sacrificio (Almagro, 1978: 264), así como también una pequeña figura broncínea del Museo Arqueológico Nacional y procedente de la Puerta de Segura (Jaén) recientemente estudiada de forma monográfica (Almagro, Lorrio, 2011). Este tipo de cuchillo lo localizamos en la Cueva del Montgó en Javea (Almagro, Lorrio, 2011: fig. 17,D), actualmente depositado en el Museo Arqueológico Nacional, y en Lez Ensérume, Herault, Tumba Mouret IB 103 datada en el siglo IV a.C. (Aranegui, et al., 1998: 242, pieza 26).

El cuchillo afalcatado que está generalizado en todas las necrópolis de este tipo, se relaciona con el sacrificio por degüello en un ritual en este caso funerario, lo que llevaría a su vez a la existencia de un banquete.

Estrabón (IV, 15) también indica la realización de sacrificios por parte de los iberos al decir que estos sacrificaban al modo griego, recogiendo la sangre en una crátera o recipiente y atenuando los gemidos de las víctimas con los cantos de los asistentes y el sonido de las flautas.

El sacrificio en la zona queda reflejado iconográficamente en la patera de Tivissa, en donde la victima es un cordero. Este animal es el más representado en la iconografía de la zona. Así, en la necrópolis del Bovalar de Benicarló hay un colgante con la representación de una paloma y otro con la de un cordero, además del prótomo de cordero que haría las funciones de asa de un caldero (Esteve, 1966: lám V). En la necrópolis de Mianes se repite la presencia del cordero y del ave (Maluquer, 1987: fig. 11). En Milmanda también hay representado el carnero (Graells, 2008), y en Can Canyis está el cordero (Vilaseca, 1963: fig. 4). El sacri- ficio del carnero se relaciona con el culto del antepasado (Almagro, Lorrio, 2011: 60), por tanto sería el más apropiado en una ceremonia funeraria.

\section{El banquete}

Los elementos que hemos ido señalando localizados en la necrópolis de la Solivella nos indican un ritual en el que se realizan posiblemente actos de libación, ofrenda y sacrificio, y por tanto de banquete funerario. Bien es verdad que los únicos restos de animal que se han identificado en este tipo se necrópolis se encuentran tan solo en la de Granja Soley, concretamente cervido y jabalí (Sanmartí, 1982: 74), y en La Vital de Gandía en donde existen muestras de sacrificio y libación (Pérez, 2011). Pero la presencia de restos de animales en las necrópolis ibéricas no es extraña (Oliver, 1996).

El banquete ritual no es ajeno en la Edad del Hierro de la zona, tal y como queda identificado ya en el siglo VII a.C. en contextos no funerarios (Graells, 2005), siendo el más significativo el del cercano yacimiento de Mas d'en Serra Sant Jaume de Alcanar.

Los banquetes en las necrópolis de la época de la Solivella quedarían demostrados por los simpulum que sería el otro elemento junto con el cuchillo relacionado con el reparto de la comida, que aparecen en algunas de ellas, como en Granja Soley. También el rallador de Milmanda, o el prótomo de cordero de la vecina necrópolis del Bovalar de Benicarló (Esteve, 1966: lam V) que podría denunciar la presencia de un caldero o algún tipo de vasija metálica como la que se localiza en el Puig de la Nau de Benicarló, en el mismo recinto en el que aparece el colgante de un carnero (Oliver, Gusi, 1995: fig 53, foto 14). Estos elementos pueden ser indicadores de la celebración de un ágape funerario

Los banquetes funerarios están constatados en necrópolis peninsulares de la Edad del Hierro (Almagro, 1977: 331, 381; Blánquez, 1990: 122; Monraval, López, 1984).

\section{El desarrollo del ritual funerario}

Ante los datos que tenemos de la necrópolis de la Solivella podríamos reseñar que el desarrollo del ritual de enterramiento sería el siguiente.

Traslado del difunto desde su lugar de residencia situado al menos, a tenor de los datos que tenemos en la actualidad, entre 1'5 y 2 kilómetros. Cremación en la pira funeraria en un lugar indeterminado, ya que no se han localizado restos de los correspondientes ustrina. Recogida de los restos óseos y de la indumentaria con la que fue quemado el difunto. Limpieza y fragmentación de los huesos para situarlos dentro de la urna. Realización del sacrificio del animal con la consiguiente libación y reparto de la carne y bebida. Ofrenda de la ración correspondiente al difunto o a los dioses. Cierre de la urna con el plato que se ha realizado la libación. Colocación del ajuar en torno a la urna. Cubrición de la sepultura con tierra. 


\section{Simbolismo SOCIAL EN EL RITUAL FUNERARIO.}

La ceremonia funeraria en si indicaría el estatus social del finado, ya que esta ceremonia es un gran acto público que refleja la situación económica y social en la que ha vivido el difunto. Por el mero hecho de ser enterrado en la necrópolis ya se está haciendo una distinción, ya que no todos los miembros de la sociedad eran sepultados en estas necrópolis. La abundancia en el sacrificio y la calidad de los utensilios utilizados en los rituales era también un signo de distinción. El acto funerario era pues un escaparate y una ostentación de la situación social de la persona que se enterraba, era la última intervención en el mundo de los vivos y por tanto debía de estar de acorde con su situación social, o incluso superarla.

También los materiales, los efectos personales, con los que se enterraban, mostraban el estamento al que pertenecía el individuo.

Algunos de los restos localizados en la necrópolis de la Solivella son una muestra de este simbolismo social y económico.

Las armas de los ajuares indican la importancia del estamento militar dentro de la sociedad de los primeros años de la Cultura Ibérica. Estas necrópolis del Ibérico antiguo son las primeras de la zona que presentan armamento, anteriormente los ajuares funerarios del Hierro antiguo lo componían piezas de la indumentaria, pulseras, colgantes, hebillas, etc. Tan solo en el nordeste se encontraban armas en las tumbas. Ello indicaría al cambio que sufrieron los estamentos altos de la sociedad después de la destrucción violenta de los asentamientos de la etapa anterior, la aristocracia guerrera se sitúa en lo alto de la pirámide social en el inicio de la iberización, característica que continuará hasta el ibérico tardío (Oliver, 2012).

Entre el material metálico recogido en superficie se han podido identificar tres torques que en el trabajo de D. Fletcher se mencionan como fragmentos de pulsera abierta (Fletcher 1965, 18, lám. III). Una vez reconstruidas las piezas se ha podido comprobar que son torques uno de ellos terminado en punta aguda, mientras que los otros dos acaban en un pequeño abultamiento. Son piezas macizas sin ningún tipo de decoración.

Este tipo de collar es una pieza que se da también en la necrópolis del Mas de Mussols de la Aldea y en Mianes de Santa Bárbara.

Como bien se sabe los torques son elementos de la indumentaria, concretamente de la orfebrería personal, que permiten relacionar a las personas que los exhiben con un estatus elevado dentro de la sociedad ibérica.

Otro elemento de la indumentaria que está relacionado con el estatus social de la persona que lo lleva es la hebilla del cinturón, de las que en la Solivella se han localizado trece, ocho entre el material de superficie y cinco relacionadas con las urnas. Son hebillas de uno, dos y tres garfios, ricamente decoradas con cincelado y granulado. En las que se aprecia la forma de decoración destaca las formas circulares, tan solo en una esta figura no se da.
La presencia de los broches de cinturón en ofrendas a santuarios como se ve en el Collado de los Jardines, o las conocidas hebillas procedentes de la península Ibérica, localizadas en los santuarios griegos de Corfú y Olimpia, así como su representación en la estatuaria ibérica en algunos casos de forma ostentosa, incluso como único elemento de la indumentaria que lleva el personaje desnudo representado como se ve en los exvotos de bronce de los santuarios del sur peninsular, algunas de estas hebillas de gran tamaño, son una muestra del gran simbolismo que encierran las hebillas para los iberos. Un simbolismo que debe representar a un linaje más que a la persona, ya que las hebillas son ostentadas tanto por los hombres como por las mujeres, y posiblemente por los niños. El que la pieza haya sido reparada en varias ocasiones como es el caso de la necrópolis de Mianes de Santa Bárbara (Graells, 2005), señala la importancia de ésta como símbolo, ya que tiene que ser precisamente una pieza en concreto seguramente heredada, la que se lleva. Este simbolismo más allá del puro funcionalismo queda patente por la existencia de complicadas hebillas o la presencia de más de una en una tumba, lo que lleva a considerar que su significado dentro de la tumba puede ser diverso, ofrenda, herencia, botín de guerra (Graells, 2007).

La única pieza localizada en la Solivella proveniente del comercio externo, lo que es indicativo de la importancia del difunto debido a su procedencia exógena, es un escarabeo egipcio.

Una característica de este tipo de necrópolis es la presencia de elementos egipcios o egiptizantes, especialmente escarabeos. Así en las necrópolis de Can Canyis, Mas de Mussols, la Solivella se localizan escarabeos. En Can Canyis el conjunto de estas piezas egipcias que seguramente formarían un collar está compuesto por nueve escarabeos, seis escaraboides y tres fragmentos, pertenecientes al faraón Psamético II, que reinó entre el 594 y 588 a.C. (Padró, 1971). De la necrópolis del Mas de Mussols proviene otro conjunto formado por cuatro escarabeos y un escaraboide, de los cuales tan solo uno se localizó en la excavación, aunque se ha considerado que todos provenían de la misma tumba, y que al igual que en la necrópolis anterior podrían conformar un collar. Uno de los escarabeos es de época saita datado entre el siglo VII y VI a.C., otro pertenece a Psamético II, por tanto de inicios del siglo VI a.C. al igual que el conjunto de Can Canyis, el resto aunque no se pueden fechar tienen también sus paralelos en el conjunto de la misma necrópolis (Padró, 1978). También al faraón Psamético II pertenece el escarabeo de la Solivella, representando un león con sol como el tercero del Mas de Mussols (Padró, 1974). El ajuar de la urna 6 en la que se encontró el escarabeo contenía once cuentas de collar de pasta vitrea junto al escarabeo, por lo que posiblemente, y a tenor de lo expuesto para las otras dos necrópolis, el escarabeo y las cuentas de collar podrían estar unidas a modo de collar. 
También de Psamético II es el escarabeo del asentamiento del Tossal del Moro de Pinyeres en Batea (Padró, 1974: 74), parecido al número 12 de Can Canyis. Así mismo pertenecientes al siglo VII-VI a.C. hay un escarabeo en Tortosa (Padró, 1974). Más dudosa es la adscripción de una pieza proveniente de Vinaròs que podría ser egipcia pero que tan solo se conoce por antiguas referencias bibliográficas, recogida cerca del yacimiento del Puig de la Misericórdia (Padró, 1990-1991). Por tanto, en torno a la desembocadura del río Ebro vemos que hay un interés por los escarabeos egipcios que se caracterizan por la homogeneidad temporal de las piezas.

El interés por los materiales egipcios no desaparece en las necrópolis de este tipo con cronología más avanzada, como se ve con el sello de plata de iconografía egiptizante proveniente de la necrópolis del Puig de la Nau (Padró, 1990-91). Según J. Padró quien hace la joya de Benicarló tiene un escarabeo del tipo pseudos-egipcio delante. Es una producción de talleres occidentales, frente a las del grupo anterior que eran productos de Naucratis. También una producción occidental es el escarabeo localizado en la necrópolis del Torrelló del Boverot de Almassora (Clausell 2002-2003), aunque al igual que en el Puig de la Nau, no se encuentra relacionado con ninguna tumba. Es una pieza que puede datarse a finales del siglo $\mathrm{V}$ e inicios del IV a.C. Así pues, las piezas egiptizantes del siglo $\mathrm{V}$ a.C., provienen de talleres occidentales, frente al taller de Naucratis que provee las piezas del siglo anterior.

Tengamos en cuenta que estas piezas juntamente con los frascos de perfumes localizados en el Mas de Mussols y Milmanda, concretamente aribalo para ambos yacimientos y botellas de cerámica gris fenicia, son los únicos elementos de importación que se dan, exceptuando el caso de la necrópolis de la Punta de Orleyl en la cual las importaciones provienen del mercado griego, desde el siglo VI al IV a.C. (Lazaro, et al., 1981).

El material egipcio se da también en las necrópolis del sudeste, el Molar de San Fulgencio (Padró, 1975) y en les Cassetes de Villajoyosa (García, Padró, 20022003), así como en época tardía en la Albufereta de Alicante (Rubio, 1986).

Ello lleva a suponer que las creencias escatológicas de los iberos tienen cierta relación con el simbolismo o la propia escatología de los egipcios, ya que la presencia de estas piezas no es tan solo la moda de un momento o la coincidencia de una oferta de mercado, pues esta relación prácticamente se inicia con la Cultura Ibérica y continúa hasta su final.

Frente a la ostentación de los materiales que componen el ajuar y el ritual funerario, hay que señalar tal y como se ha comentado más arriba, la falta de interés por señalar ostentosamente la situación de la tumba. Ninguna construcción se situará encima de los enterramientos de este tipo de necrópolis.

\section{Demografía de la NeCrópolis}

Cuando se excavó la necrópolis de la Solivella los restos óseos humanos procedentes del enterramiento tan solo se recogían y no eran sometidos a ningún tipo de análisis. Hoy en día realizar el estudio de una necrópolis sea de cremación o de inhumación no se concibe sin proceder a un detallado estudio antropológico.

En el Museo de BB.AA. de Castellón tan solo se conservan los restos óseos de quince de las urnas, de ellos tres no han conservado la referencia de la sepultura.

Estos quince conjuntos han sido analizados por el doctor Francisco Gómez Bellard, resultando que seis son mujeres y otros dos posiblemente también, lo que supone que el 53'3\% sin contabilizar los infantiles, de los enterramientos pertenecen al sexo femenino. Es pues un alto porcentaje muy elevado de mujeres en relación a otras necrópolis ibéricas, lo que caracteriza y singulariza esta necrópolis, pues tal y como indica M. Almagro al estudiar la demografía ibérica a partir de las cremaciones, "la proporción total de individuos de sexo masculino es doble de la de sexo femenino", concretamente da el porcentaje del 67' $7 \%$ de índice de masculinidad (Almagro, 1986: 480), dato que podemos corroborar en necrópolis en los que se han hecho los correspondientes estudios antropológicos, Turó dels Pins de Cabrera, Puig de la Nau de Benicarló, El Cigarralero de Mula, las necrópolis de Coimbra del Barranco Ancho de Jumilla.

Dos conjuntos tres son niños, uno de ellos de dos años, por tanto el $20 \%$. Dos enterramientos más no se han podido sexar, y tan solo uno pertenece a un varón adulto, el 6'6\%. Hay que destacar también que del conjunto siete corresponden a adultos jóvenes, más los dos niños. Cuatro a individuos adultos, uno de ellos el varón, y en un solo caso no se ha podido saber a que edad pertenece.

Por tanto, el conjunto óseo destaca por el alto porcentaje de individuos jóvenes e indudablemente el porcentaje de mujeres.

En cuanto a la asociación con el ajuar es poco significativo, pues tan solo se puede relacionar como mucho con piezas de la indumentaria, brazaletes, broches y colgantes. La urna 18 relacionada con armas, lanza y cuchillo, no se ha podido identificar ni el sexo ni la edad. Hay que indicar que los dos niños no presentan ajuar, aunque es verdad que dos enterramientos más pertenecientes a jóvenes, tampoco se relacionan con ajuar.

En lo referente a las urnas indiquemos que una de los dos adultos se encuentra en la urna más peculiar del conjunto cerámico debido a la característica tapa que tiene. La urna 16 que también pertenece a un adulto, mujer, es la de mayor tamaño, aunque en este caso no presenta ajuar por lo que la relación de riqueza entre urna y ajuar es inversa. 


\begin{tabular}{|c|c|c|c|}
\hline Sepultura & Sexo & Edad & Ajuar \\
\hline Urna 1 & Hembra & $\begin{array}{l}\text { Adulta } \\
\text { joven }\end{array}$ & Anillas, colgantes \\
\hline Urna 3 & ¿? & $<4$ años & Sin ajuar \\
\hline Urna 5 & Hembra & $\begin{array}{l}\text { Adulta } \\
\text { joven }\end{array}$ & Fibula, broche, brazalete \\
\hline Urna 10 & ¿? & Joven & Sin ajuar \\
\hline Urna 12 & ¿? & Adulta & $\begin{array}{l}\text { Fibula, broche, brazalete, anillas, } \\
\text { colgante }\end{array}$ \\
\hline Urna 15 & ¿? & 2 años & Sin ajuar \\
\hline Urna 16 & Hembra & Adulta & Sin ajuar \\
\hline Urna 17 & Hembra & $\begin{array}{l}\text { Adulta } \\
\text { joven }\end{array}$ & Anillas, colgante \\
\hline Urna 18 & ¿? & ¿? & Armas, broche \\
\hline Urna 21 & Hembra & $\begin{array}{l}\text { Adulta } \\
\text { joven }\end{array}$ & Sin ajuar \\
\hline Urna 24 & Hembra & $\begin{array}{l}\text { Adulta } \\
\text { joven }\end{array}$ & Brazalete, anillas, colgante \\
\hline Urna 26 & ¿? & Infantil & Sin ajuar \\
\hline ¿? & Hembra & Adulta & \\
\hline ¿? & Hembra & $\begin{array}{l}\text { Adulta } \\
\text { joven }\end{array}$ & \\
\hline ¿? & Varón & Adulto & \\
\hline
\end{tabular}

Tabla 1. Resultados de los análisis antropológicos y su relación con los ajuares.

\section{BIBLIOGRAFÍA}

Almagro-Gorbea, M. (1977): El bronce final y el período orientalizante en Extremadura. Bibliotheca Praehistorica Hispana XIV. Madrid.

Almagro-Gorbea, M. (1978): “Los relieves mitológicos orientalizantes de Pozo Moro". Trabajos de Prehistoria 35, 251-278.

Almagro-Gorbea, M. (1986): “Aportación inicial a la paleodemografía ibérica". Estudios en homenaje al Dr. D. A. Beltrán, 477-493.

Almagro-Gorbea, M., Lorrio Alvarado, A. (2011): Teutates. El héroe fundador. Madrid.

Aranegui, C. (1979): "Hallazgos de una necrópolis ibérica en La Mina (Gátova, Castellón)". Cuadernos de Prehistoria y Arqueología Castellonenses 6, 269-286.

Aranegui Gascó, C. (1996): “Los platos de peces y el más allá”. Complutum Extra. Homenaje al profesor Manuel Fernández-Miranda 6, 1, 401-414.

Aranegui Gascó, C., Mohen, J.P., Rouillard, P. (1998): Los ibéros. Príncipes de occidente. Barcelona.

Blánquez Pérez, J. J. (1990): La formación del mundo ibérico en el sureste de la Meseta (Estudio arqueológico de las necrópolis ibéricas de la provincia de Albacete). Albacete.
Cabré Aguiló, J., (1936). "El tesoro de plata de Salvacañete (Cuenca)". Archivo Español de Arqueología, XII, 151-159. Madrid.

Clausell Cantavella, G. (1999): "La incineración 20 de la necrópolis del Torrelló del Boverot (Almazora, Castellón)". Quaderns de Prehistòria $i$ Arqueologia de Castelló 20, 115-128.

Clausell, G. (2002-2003): "Un escarabeo etrusco en la necrópolis del Torrelló del Boverot (Almazora, Castellón)". Quaderns de Prehistòria $i$ Arqueologia de Castelló 23, 241-246.

Cortell Pérez, E., Juan Moltó, J., Llobregat Conesa, E., Reig Seguí, C., Sala Selles, F., Segura Martí, J.M. (1992): "La necrópolis ibérica de la Serreta. Resumen de la campaña de 1987'. SIP. Serie de Trabajos Varios, 89. Estudios de Arqueología ibérica y romana. Homenaje a Enrique Pla Ballester, 83-116.

Cuadrado, E. (1966): Repertorio de los recipientes rituales metálicos con asas de manos de la Península Ibérica. Trabajos de Prehistoria, XXI. Madrid.

Esteve Gálvez, F. (1966): “La necrópolis ibérica de El Bovalar (Benicarló, Castellón de la Plana)". Archivo de Prehistoria Levantina XI, 125-154.

Esteve Gálvez, F. (1974): La necrópolis ibérica de la Oriola cerca de Amposta (Tarragona). Estudios ibéricos, 5. Valencia. 
Fletcher Valls, D. (1965): La necrópolis de la Solivella (Alcalà de Chivert). Serie de Trabajos Varios del SIP, 32. Valencia.

Flors, E. (Coord) (2009): Torre la Sal (Ribera de Cabanes, Castellón). Evolución del paisaje antrópico desde la prehistoria hasta el medioevo. Monografies de Prehistòria i Arqueologia Castellonenques, 8. Castellon.

García Gandía, J. R., Padró Parcerisa, J. (2002-2003): Una cantimplora de fayenza egipcia procedente de la necrópolis de Les Casetes (La Vila Joiosa, Alicante). Pyrenae 33-34, 347-364. Barcelona.

Gil Mascarell, M. (1973): Restos funerarios ibéricos en la provincia de Castellón y Valencia. Papeles del Laboratorio de Arqueología de Valencia 9, 29-48.

González-Alcalde, J. (2009): “Una aproximación cultural a los vasos caliciformes ibéricos en cuevassantuario y yacimientos de superficie". Quaderns de Prehistòria i Arqueologia de Castelló 27, 83108.

Graells Fabregat, R. (2005): “Un broche de cinturon de garfios reparado en la necrópolis de Mianes (Amposta, Montsià)". Saguntum 37, 171-174.

Graells Fabregat, R. (2007): “Cinturones imposibles vs ornamentación funeraria, o como entender las tumbas con dos cinturones de garfios en el noreste peninsular (s. VI a.C.)". Saldvie - Salduie. Estudios de Prehistoria y Arqueología 7, 39-48.

Graells Fabregat, R. (2008): Fermalls de cinturó de 4 i 6 garfis a Catalunya: tipologia, cronologia i dispersió. Arqueo Mediterrània. Actes del I Congrés de Joves Investigadors en Arqueologia dels Països Catalans: la protohistoria als Països Catalans (Vilanova del Camí, 18 i 19 de novembre de 2005) 10, 197-200.

Graells Fabregat, R. (2008): La necròpolis protohistòrica de Milmanda (Vimbodí, Conca de Barberà, Tarragona). Un exemple del món funerari català durant el trànsit entre els segles VII $i$ VI aC. Hic et Nunc, 5. Tarragona.

Graells Fabregat, R. (2010). Las tumbas con importaciones y la recepción del Mediterráneo en el nordeste de la Península Ibérica (siglos VII-VI a.C.). Revista d'Arqueologia de Ponent. Número Extra. Lérida.

Griñó, B. de, Olmos, R. (1982): La Pátera de Santisteban del Puerto (Jaén). Madrid.

Gusi Jener, F. (1971): “Informe sobre la campaña de excavaciones en la Región del alto Valle del Mijares". Noticiario Arqueológico Hispánico XVI, 205-241.

Gusi, F., Oliver, A. (1986): “Tres urnes de la necròpolis ibèrica de la via ferrea València-Tarragona, prop d'Alcossebre (Alcalà de Xivert, Castelló).
Cuadernos de Prehistoria y Arqueología Castellonenses 12, 123-140.

Lazaro Mengod, A., Mesado Oliver, N., Aranegui Gascó, C., Fletcher Valls, D. (1981): Materiales de la necrópolis ibérica de Orleyl (Vall d'Uxó). SIP Trabajos Varios, 70. Valencia.

López Bravo, F. (2002): "La urna ibérica de orejetas perforadas". Complutum 13, 97-116.

Maluquer de Motes, J. (1987): "La necrópolis paleoibérica de Mianes, Santa Bárbara (Tarragona)". Catalunya: Baix Ebre, 115-185.

Maluquer de Motes, J. (1987a): "La necrópolis paleoibérica de "Mas de Mussols" La Palma, Tortosa (Tarragona)". Catalunya: Baix Ebre, 33-110.

Martínez García, J. M. (1989): “La necrópolis ibérica de las Peñas (Zarra, Valencia)". Archivo de Prehistoria Levantina, XIX, 1-76.

Martínez Perona, J. V. (1992): "El santuario ibérico de la cueva de Merinel (Bugarra). En torno a la función del vaso caliciforme". Trabajos Varios del SIP, 89. Estudios de Arqueología Ibérica y Roman. Homenaje a Enrique Pla Ballester, 261-281.

Meseguer Folch, V., Giner, V. (1983): La necrópolis ibérica de el Puig de Benicarló. Benicarló.

Moneo, T. (2003): Religio Iberica. Santuarios, ritos y divinidades (siglos VII - I A.C.). Bibliotheca Archaeologica Hispanica, 20. Madrid.

Morote Barbera, G. (1981): “Una estela de guerrero con espada de antenas en la necrópolis ibérica de Altea la Vella (Altea, Alicante)". Archivo de Prehistoria Levantina XVI, 417-446.

Munilla Cabrillana, G. (1991): "Elementos de influencia etrusca en los ajuares de las necrópolis ibéricas". Actas de la Mesa Redonda sobre La presencia del material etrusco en la Península Ibérica, 107-175. Barcelona.

Neumaier, J., Antonio Otal, J. M. de, Vizcaíno León, D. (1998): "Excavaciones de salvamento en el Castell de Xivert (Alcalá de Chivert, Castellón). Avance del estudio de las fases pre y protohistóricas". Quaderns de Prehistoria i Arqueologia de Castelló 19, 195-219.

Oliver Foix, A. (1981): "Incineraciones entre el río Ebro y el Palancia. Nuevas aportaciones para el estudio de los enterramientos ibéricos". Cuadernos de Prehistoria y Arqueología Castellonenses 8, 189-256.

Oliver Foix, A. (1986): "Sobre un posible rito funerario de ofrenda y libación en la necrópolis ibérica de la Solivella (Alcalá de Xivert)". Boletín del Centro de Estudios del Maestrazgo 14, 47-56. Benicarló.

Oliver Foix, A. (1983): "Los enterramientos de Els Espleters Salzedella”. Butlletí de l'Associació Arqueològica de Castelló 3, 32-34. 
Oliver Foix, A. (1990): "Hallazgo arqueológico en el casco urbano de Alcalá de Xivert". Boletín del Centro de Estudios del Maestrazgo 31, 81-88.

Oliver Foix, A. (1996): "Fauna y vegetación en los ritos cultuales ibéricos". Quaderns de Prehistòria $i$ Arqueologia de Castelló 17, 281-308.

Oliver Foix, A. (2005): "La necropolis ibérica del Mas Nou de Bernabé en Tirig - Salzadella (Castellón)". Saguntum 37, 45-58.

Oliver Foix, A. (2012): "Signos de poder en la protohistoria. Un ejemplo en el levante peninsular". Potestas. Revista del Grupo Europeo de Investigación Histórica, 5, 5-27.

Oliver, A., Gusi, F. (1995): El Puig de la Nau. Un hábitat fortificado ibérico en el ámbito mediterráneo peninsular. Monografies de Prehistòria i Arqueologia castellonenques 4. Castellón.

Padró Parcerisa, J. (1971): "Breus notes sobre els escarabeus i escaraboids de la necrópolis de Can Canyis". Pyrenae 7, 129-133.

Padró Parcerisa, J. (1974): “A propósito del escarabeo de la Solivella (Alcalá de Xivert, Castellón) y de otras piezas egipcias del Bajo Ebro". Cuadernos de Prehistoria y Arqueología Castellonense 1, 71-78.

Padró Parcerisa, J. (1975): "Los objetos de tipo egipcio de la necrópolis de El Molar (Sant Fulgenci, Alicante) y su problemática". Cuadernos de Prehistoria y Arqueología Castellonense 2, 133142.

Padró Parcerisa, J. (1978): “Los escarabeos y el escaraboide de la necrópolis del Mas de Mussols ( $\mathrm{La}$ Palma, Tortosa, Tarragona)". Cuadernos de Prehistoria y Arqueología Castellonense 5, 257-264.

Padró Parcerisa, J. (1990-91): “Un joiell d'argent egiptitzant del Puig de la Nau de Benicarló (El Baix Maestrat)". Cuadernos de Prehistoria y Arqueología Castellonense 15, 443-445.

Peña Ligero, Á. (2003): La necrópolis Ibérica de El Molar (San Fulgencio-Alicante) Revisión de las excavaciones realizadas en 1928 y 1929 . Villena.
Pérez Jordá, G., Bernabeu Auban, J., Carrión Marco, Y., García Puchol, O. Molina Balaguer, LL., Gómez Puché, M. (2011): La Vital (Gandia, Valencia). Vida y muerte en la desembocadura del Serpis durante el III y el I milenio a.C. Serie de Trabajos Varios, 113.Valencia.

Prados Torreira, L., (1992): Exvotos ibéricos de bronce del Museo Arqueológico Nacional. Madrid.

Quesada Sanz, F. (1997): El armamento ibérico. Estudio tipológico, geográfico, funcional, social y simbólico de las armas en la Cultura ibérica (siglos VI-I a.C.). Monographies Instrumentum, 3,1. Montagnac.

Raddatz, K., (1969): Die schatzfunde der Iberischen Halbinsel. Berlín.

Rubio Gomis, F. (1986): La necrópolis ibérica de la Albufereta de Alicante (Valencia, España). Serie Arqueológica, 11. Valencia.

Sardà, S., Graells, R. (2004-2005): “Sobre la identificació d'un tipus d'urna d'orelletes arcaic a Catalunya". Quaderns de Prehistòria $i$ Arqueologia de Castelló 24, 173-188. Castellón.

Serra Rafols, C. (1941): "El poblado ibérico del Castellet de Banyoles, de Tivissa (Tarragona)". Ampurias 3, 15-34. Barcelona.

Serrano Carrillo, J., Morena López, J.A., (1988). “Un relieve de baja época ibérica procedente de Torreparedones (Castro del Río-Baena, Córdoba)". Archivo Español de Arqueología, 61, 245-248. Madrid.

Uroz Rodíguez, H. (2012): Prácticas rituales, iconografía vascular y cultura material en Libisosa (Lezuza, Albacete). Alicante.

Vilaseca Anguera, S., Solé Caselles, J.M., Mañé Güell, R. (1963): La necrópolis de Can Canyis (Banyeres, prov. De Tarragona). Trabajos de Prehistoria, VIII. Madrid.

Valcarcel Pío de Saboya, A. (1852): Inscripciones y antigüedades del Reino de Valencia. Memorias de la Real Academia de la Historia VIII. Madrid. 
